\title{
SIMULTANEOUS DISC HERNIATION IN PATIENTS WITH MULTIPLE SCLEROSIS
}

\author{
Kalina V. Drenska ${ }^{1}$, Ara G. Kaprelyan ${ }^{1}$, Alexandra J. Tzoukeva ${ }^{1}$, Radoslav \\ Georgiev $^{2}$, Iliya T. Todorov ${ }^{3}$. \\ 1) Department of Neurology, \\ 2) MRI Sector, Department of Radiology, \\ 3) Clinic of Physical therapy and Balneology, \\ Medical University of Varna, Bulgaria.
}

\begin{abstract}
ABSTARCT
Background: Multiple sclerosis (MS) is a chronic autoimmune, inflammatory demyelinating disease of the central nervous system. Commonly, MS patients present with accompanying degenerative vertebral disc diseases. Simultaneous disc herniations situated in the cervical or lumbosacral spine can mimic the clinical symptoms of MS and worsen patients' quality of life.

Objective: to investigate the incidence rate and clinical impact of accompanying disc herniations in patients with MS.

Material and methods: Our study covered 330 patients (220 females and 110 males, mean age $40.5 \pm 12.4$ years) with clinically definite MS, according to McDonald's criteria. Comprehensive neurological examinations, EDSS (Expanded Disability Status Scale) assessments, and MRI neuroimaging were carried out. Statistical data processing was performed by using the method of variation analysis.

Results: Relapsing-remitting MS (RRMS) was diagnosed in 280 patients while 50 patients presented with secondary progressive MS (SPMS). Disc herniation was found in $64(19.4 \%)$ of our patients. Cervical disc pathology was detected in 38 patients (11.5\% of the cases) and lumbosacral - in 26 (7.9\% of the cases). EDSS scores ranged from 2.5 to 5.5. EDSS evaluation showed statistically significantly worse scores in MS patients with disc herniation comorbidity $(\mathrm{p}<0,05)$.

Conclusion: Our own data confirm the assumption that MS patients often present with accompanying degenerative disc pathology. We suggest that comorbidity of disc herniation and MS exert an additional unfavorable effect on patient's disability and individual quality of life.
\end{abstract}

Key words: Multiple sclerosis, disc herniation, comorbidity

\section{INTRODUCTION}

Multiple sclerosis (MS) is a chronic autoimmune, inflammatory demyelinating disease of the central nervous system. It is one of the most often causes of neurological disability affecting young adults (7). Commonly, MS patients present with accompanying degenerative vertebral disc diseases. Simultaneous disc herniations situated in the cervical or lumbosacral spine can mimic the clinical symptoms of MS and worsen patients' quality of life (8). K. Jaracz et al. (2010) examined disease severity in 210 MS patients aged between 21 and 59 years by using EDSS. It was mild (EDSS $<4$ ) in $85 \%$ of the cases.

Compression of cervical spinal cord secondary to cervical spondylosis or disc herniation can result in acute or chronic myelopathy. This may go unnoticed in MS patients frequently presenting with similar symptoms $(8,14)$. Appropriate use of neuroimaging studies assist in the differentiation of these two disorders (2). Many neurological symptoms in MS patients are identical to those experienced by patients with disc herniations (14).

The objective of our study was to investigate the incidence rate and clinical impact of accompanying disc herniation in patients with MS.

\section{MATERIALAND METHODS}

The study covered 330 patients (220 females and 110 males, mean age $40.5 \pm 12.4$ years) with clinically definite MS according to McDonald's criteria (Table 1.). All cases were hospitalized in the First Clinic of Neurology at St. Marina University Hospital of Varna during the period from January 2005 to March 2012. Comprehensive neurological examinations, EDSS (Expanded Disability Status Scale) assessments, and MRI neuroimaging were carried out. Statistical data processing was performed by using the method of variation analysis.

Table 1. Patients' distribution according to gender.

\begin{tabular}{|l|c|c|c|}
\hline Sex & Males & Females & Total \\
\hline Number & 110 & 220 & 330 \\
\hline$\%$ & 33,4 & 66,6 & 100 \\
\hline
\end{tabular}




\section{RESULTS}

RRMS was diagnosed in 280 patients, while 50 patients presented with SPMS. Disc herniation was found in $64(19.4 \%)$ of our patients (Table 2.). Cervical disc pathology was detected in 38 patients $(11.5 \%$ of the cases) and lumbosacral - in 26 (7.9\% of the cases). EDSS scores ranged from 2.5 to 5.5. EDSS evaluation showed statistically significantly worse scores in MS patients with disc herniation comorbidity $(\mathrm{p}<0,05)$. We present two of our cases with corresponding MRI findings.

Table 2. Patients' distribution according to the location of disc herniations.

\begin{tabular}{|l|c|c|}
\hline \multirow{2}{*}{} & \multicolumn{2}{|c|}{ Total } \\
\cline { 2 - 3 } & $\mathrm{n}$ & $\%$ \\
\hline Cervical disc herniation & 38 & 11,51 \\
\hline Lumbosacral disc herniation & 26 & 7,88 \\
\hline Total & 64 & 19,39 \\
\hline
\end{tabular}

Case 1. The disease began in 1999 with paraesthesia and weakness in the arms, paraesthesia in lower extremities, ataxia, and visual disturbances. Diagnosis was proven in 2002 by MRI that showed features of MS and C5-C6 herniated disc (Figure 1). On the CT of lumbar vertebrae were found further herniated disc of L5-S1. This is an example of comorbidity of MS with disc disease.

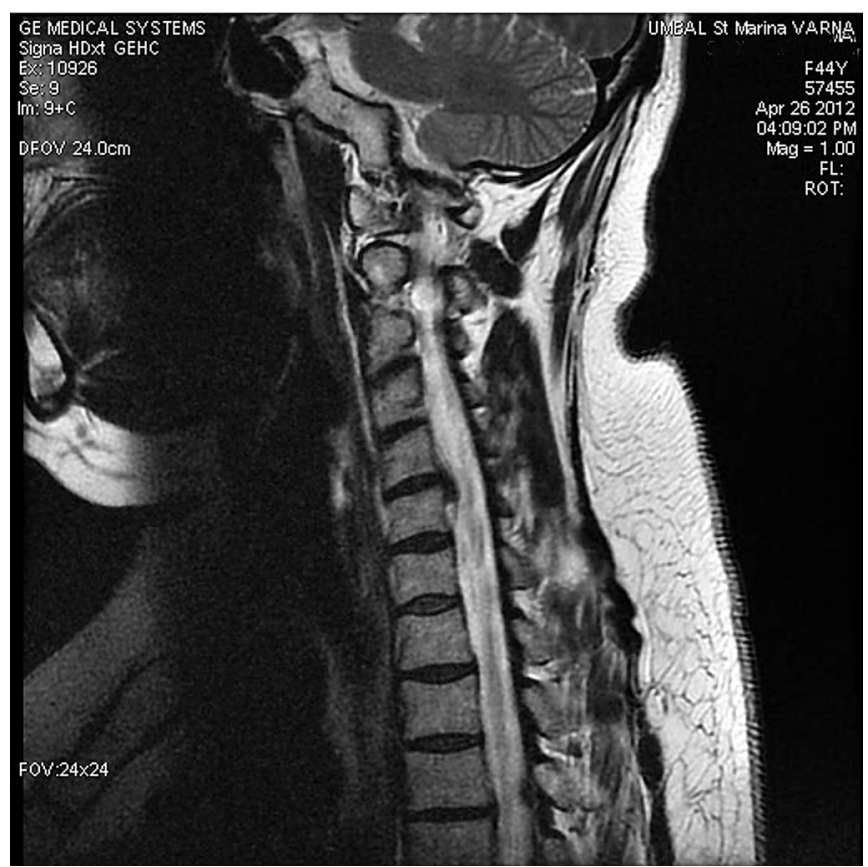

Fig. 1. T2-weighted MRI image shows dorsally located lesions on $\mathrm{C} 2-\mathrm{C} 3$ and $\mathrm{C} 4-\mathrm{C} 5$; left side paramedian descendent focal disc herniation (intraanular prolapsed disc) on level C5-C6, and buldging disc on level C6-C7.
Case 2. The disease began at 2003 with visual disturbances, paraesthesia of the right facial half and both lower extremities legs. Later on MRI images confirmed the diagnosis MS, and showed disc herniations on several levels in cervical region. In this case, as an additional trove herniated disc was found, in patient without having symptoms by the moment (Figure 2).

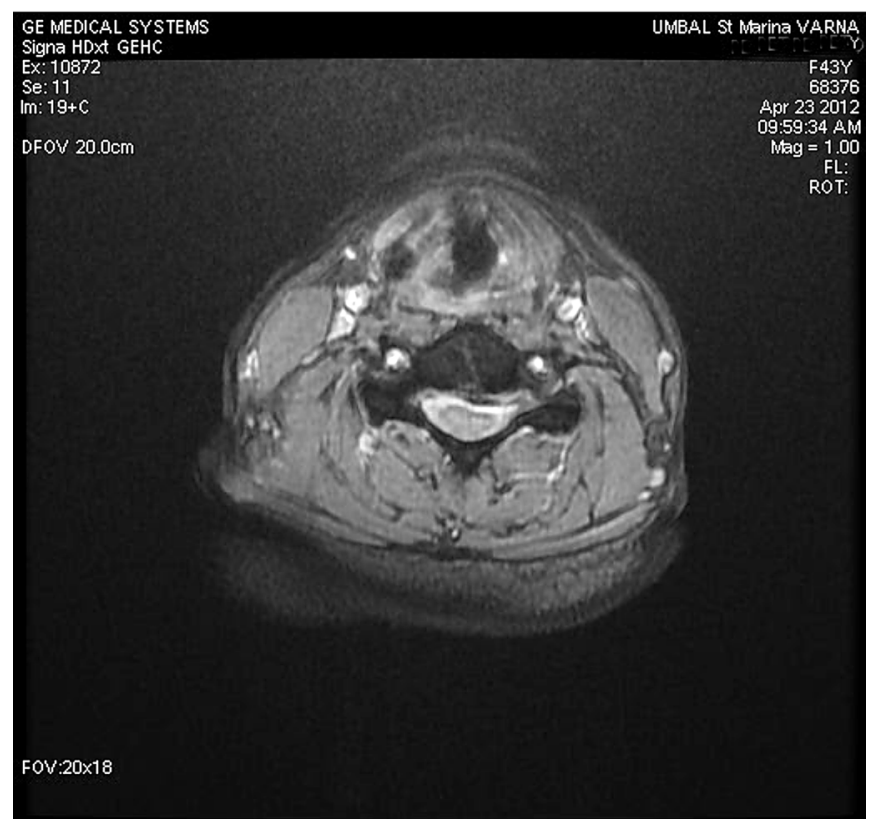

Fig. 2. T2-weighted MRI image shows on C5-C6 levels paramedian to lateral disc protrusion on a wide base, with compression on the left nerve root. There are lesions in the spinal cord centrally located, also. These are T2 series in axial projection.

\section{DISCUSSION}

There are several publications about the comorbidity between MS and disc herniation. For some MS patients, the neurological deterioration may result from coexisting spinal cord compression attributable to a herniated disc. A 38-yearold man presented with symptomatic simultaneous multilevel disc herniation in the cervical, thoracic and lumbar spine along with MS diagnosed by means of visual evoked potentials and cerebrospinal fluid examination (8).

Clinical features and MRI may assist clinicians in differentiating between the two diseases: MS and disc herniation, and may guide appropriate treatment. The role of MRI in the diagnosis of spinal pathology is widely emphasized $(1,3,10,11)$. The evaluation of a patient with known MS who develops new signs of spinal cord dysfunction, should always include spinal neuroimaging studies.

Recently, the diagnostic significance of EDSS is proved by a series of comprehensive clinical trials $(4,5,6$, 
$9,12,13)$. We also establish worsening of the scores in the patients with MS and spinal pathology.

\section{CONCLUSION}

Our own data confirm the assumption that MS patients present with accompanying degenerative disc pathology. We suggest that comorbidity of disc herniation and MS exert an additional unfavorable effect on patient's disability and individual quality of life. Decompression surgery may be an efficacious procedure in selected MS patients who have coexistent spinal cord compression.

\section{REFERENCES:}

1. Baleriaux D, Deroover N, Hermanus N, Segebarth C. MRI of the spine. Diagn Imaging Clin Med. 1986; 55(1-2):66-71. [PubMed]

2. Bashir K, Hadley MN, Whitaker JN. Surgery for spinal cord compression in multiple sclerosis. Curr Opin Neurol. 2001 Dec;14(6):765-769. [PubMed]

3. Bradley WG. Use of gadolinium chelates in MR imaging of the spine. $J$ Magn Reson Imaging. 1997 JanFeb;7(1)38-46. [PubMed]

4. Devonshire V, Havrdova E, Radue EW, O'Connor P, Zhang-Auberson L, Agoropoulou C, et al. Relapse and disability outcomes in patients with multiple sclerosis treated with fingolimod: subgroup analyses of the double-blind, randomised, placebocontrolled FREEDOMS study. Lancet Neurol. 2012 May;11(5):420-428. [PubMed] [CrossRef]

5. Ghajarzadeh M, Sahraian MA, Fateh R, Daneshmand A. Fatigue, depression and sleep disturbances in Iranian patients with multiple sclerosis.
Acta Med Iran. 2012; 50(4):244-249. [PubMed]

6. Guclu-Gunduz A, Citaker S, Nazliel B, Irkec C. Upper extremity function and its relation with hand sensation and upper extremity strength in patients with multiple sclerosis. NeuroRehabilitation. 2012; 30(4):369374. [PubMed] [CrossRef]

7. Jaracz K, Pawlak M, Gorna K, Kolcz B, Woloszyn D, Kozubski W. Quality of life and social support in patients with multiple sclerosis. Neurol Neurochir Pol. 2010 Jul-Aug;44(4):35865. [PubMed]

8. Korovessis P, Maraziotis T, Stamatakis M, Baikousis A. Simultaneous three-level disc herniation in a patient with multiple sclerosis. Eur Spine J. 1996 5(4):278-280. [PubMed]

9. Phan-Ba R, Calay P, Grodent P, Delrue G, Lommers E, Delvaux V, et al. Motor fatigue measurement by distance-induced slow down of walking speed in multiple sclerosis. PLoS One. 2012; 7(4):e34744. [PubMed] [CrossRef]
10. Poser CM. MRI of spinal cord in multiple sclerosis. Lancet, 341, 1993 Apr 17;341(8851):1025. [PubMed]

11. Roosen N, Dietrich U, Nicola N, Irlich G, Gahlen D, Stork W. MR imaging of calcified herniated thoracic disk. J Comput Assist Tomogr. 1987 JulAug;17(4):733-735. [PubMed]

12. Rotstein D, O'Connor P, Lee L, Murray BJ. Multiple sclerosis fatigue is associated with reduced psychomotor vigilance. Can J Neurol Sci. 2012 Mar; 39(2):180-184. [PubMed]

13. Wetzel JL, Fry DK, Pfalzer LA. Six-minute walk test for persons with mild or moderate disability from multiple sclerosis: performance and explanatory factors. Physiother Can. 2011 Spring;63(2):166-180. [PubMed] [CrossRef]

14. Young WF, Weaver M, Mishra B. Surgical outcome in patients with coexisting multiple sclerosis and spondylosis. Acta Neurol Scand. 1999 Aug;100(2):84-87. [PubMed]
Correspondance Adress:

Kalina Drenska, MD.

University Hospital "St. Marina” Varna, Bulgaria

e-mail: k_drenska@abv.bg,

http://www.journal-imab-bg.org 